\title{
Predictions of the Spray Characteristics of Model Gasoline, Ethanol and Ethanol-in Gasoline Fuel Blends
}

\author{
P .N. Josiah ${ }^{1}$, I. Altraide ${ }^{2}$, J.G. Akpa ${ }^{3}$, O.M.O. Etebu ${ }^{4}$ \\ ${ }^{1}$ World Bank Africa Centre for Excellence in Oilfield Chemicals Research, University of Port Harcourt, Choba, Rivers State, \\ Nigeria \\ ${ }^{2}$ World Bank Africa Centre for Excellence in Oilfield Chemicals Research, University of Port Harcourt, Choba, Rivers State, \\ Nigeria \\ ${ }^{3}$ Department of Chemical Engineering, Rivers State University, Nkpolu-Oroworukwo, Rivers State, Nigeria \\ ${ }^{4}$ Department of Mechanical Engineering, University of Port Harcourt, Choba, Rivers State, Nigeria
}

\begin{abstract}
This paper presents predictions of spray characteristics of model gasoline, ethanol gasoline-ethanol fuel blends. Fuel breakup models and correlations between flow patterns and droplet characteristics were adopted and implemented in OpenFOAM Computational Fluid Dynamics (CFD) modeling suite 1 for direct gasoline injector using a simple cylindrical mesh structure at constant volume. The Rosin Rammler distribution model was used to generate the number of spray particles injected into the cylinder. The spray modeling and atomization employed the use of blob sheet model and KH-RT model while the numerical technique for simulating atomization process by CFD included the use of governing equations such as Eulerian for gas phase, Lagrangian for disperse phase and turbulence modeling. Spray evolution at various energizing times particle density and The Sauter Mean Diameter (SMD) relationships and particle size distribution were studied in simulation mode. The results showed that with longer injection time frame and wider injection angle, the penetration width was wider and the penetration length deeper (longer) resulting in better atomization. Concerning particle density and its distribution, as number of particle increased, the density of clusters became smaller.
\end{abstract}

KEYWORDS: SMD, Cone angle, gasohol, fuel-bled, atomization, spray.

\section{INTRODUCTION}

The repeated breakup of bulk liquids into an ensemble of droplets, (sprays), commonly known as atomization, is a phenomenon that plays a key role in the field of combustion science and other fields such as agricultural irrigation pesticides application, fluid catalytic cracking, spray drying waste fuel reuse and medical applications However, in spite of the plethora of studies and publications on the subject, some aspects such as mechanisms and process paths for primary breakup are either poorly understood or remain unresolved. Worse still the focus of the existing body of knowledge is on conventional liquid fuels such as diesel and gasoline thus providing the impetus for exploring other fuels and their hybrids either in real time or as model fuels.

Studies on spray properties of various blends at ambient conditions, and spatial analysis have been conducted. However, relative to studies on diesel and bio-ethanol, much less attention has been given to atomization and spray modeling of gasoline-ethanol fuel blends.

Research efforts regarding atomization of fuels are well reported in the open literature.
Ejim et al (2007) analyzed seven biodiesels as well as their binary and ternary blends at a constant temperature. The Sauter Mean Diameter (SMD) of droplet was reported but no attempt was made regarding correlation of injector geometry, fluid properties and atomization characteristics. In Lebas et al. (2009), the atomization characteristics of sprays in the dense zone was studied by Direct Numerical Simulation (DNS) and the Eulerian-Lagrangian Spray Atomization (ELSA) models. This contribution is purely a simulation study in which experimental data drawn from previous work was used for parameter estimation. Gao et al. (2007) studied the atomization and spray characteristics of gasoline, ethanol and various blends of gasoline and ethanol. In particular blends consists of $75 \%$ gasoline and $25 \%$ ethanol (E25), 50-50\% blend of gasoline and Ethanol (E50), $25 \%$ gasoline and $75 \%$ ethanol (E75) were studied under various ambient conditions, by means of high-speed Schlieren photography. Results from the study show that at high pressures, spray development patterns are not significantly different for the various blends and the zero blends. However, spray trip penetration decreases and spray angle increases with increases in ethanol fraction in the blended fuel, at low pressure. 
Although, the images clearly affirm the authors position, they were silent on the basis for volume of ethanol in the blends that were studied. In Aleifens et al (2008), a study on the study development of gasoline, iso-octane and ethanol in a spark-ignition engine was presented. According to the authors, the spray characteristics of fuels differ between hot and cold engine operation to a large extent. Regarding spray development, slight differences were noticed among all fuels at an engine head temperature of $20^{\circ} \mathrm{C}$. However, spray cone angle was found to have reduced considerably at an engine head temperature of $80^{\circ} \mathrm{C}$. In Hassainpour and Ninesh (2009), computational fluid dynamics (CFD) code was adopted in a study of sprays in direct injection engines. The discrete droplet method, a statistical tool was employed for spray calculations by the authors. Based on experimental validation, the authors reported that spray penetration and emission characteristics are predicted better with modeling methodologies. Other authors such as Juang et al. (2010) explained the use of CFD in complex processes. A study of droplet-gas system configured in a three-dimensional model which accounted for atomization of parent droplets was reported in Lijuan et al. (2009) Deduction from this study, point to the air-to-liquid ratio in the effervescent atomizer as having strong influence on droplet size and distribution. Soybean oil methyl ester (SME) atomization was reported by Park et al. (2009), the results showed similar SMD distribution patterns for biodiesel and diesel in comparison with experimental droplet size distribution. Park et al. (2009b) studied conditions for atomization of soybean oil Methyl ester (SME) fuel, nozzle tip and SMD were calculated. SME physical properties were used as input in KIVA code (Torres and Trujilo, 2006) for the calculation of spray characteristics. Kim et al (2010) analyzed atomization performances of three fuels. Tip penetration of spray, width spray cone angle and SMD were determined by experiment and predicted by KIVA-3V code. Deductions from their study point to droplet size as being proportional to fuel physical properties. Microscopic droplets behavior of diesel and biodiesel was studied by Hung et al. (2010) The KIVA$3 \mathrm{~V}$ code, the Taylor Analogy Breakup (TAB) model and its modifications were used as numerical tools for quantifying experimental results. Other relevant experimental studies are those of Shinjo and Umemura (2011), Zhoulang et al (2012), Lee and Park (2014), Cipolat and Valentim (2013),

Theoretical and experimental injection spray characteristics were compared in a study Zhao et al. (2012). Moreover, most of them are local to diesel fuel sprays and biodiesel. Among this category are the contribution in Kawahara et al. (2004), Jiang et al. (2012), Vita and Alloca (2012), Li et al. (2014). The merit in using open source code is that it provides a platform for preliminary study. However, the task of adopting such codes vis-à-vis editing to suit specific situations can be very time consuming, besides the computer programming expertise that is required. In the last few years, research efforts geared towards broadening the 1159 understanding of sprays, atomization and breakup have been reported in the open literature. In Xie et al (2015), an experimental study in the macroscopic spray characteristics of biodiesel and diesel was reported. Various blends of biodiesel and diesel ranging from $0 \%$ and $100 \%$ diesel was formulated and studied at five different injection pressures and ambient pressures, in a constant volume chamber and a high speed camera was used to capture spray images. Results from the study show that ambient and injection pressures have significant effects on spray characteristics. The contribution is purely experimental, requiring high precision gadgets and no attempt has made regarding correlations or modeling applications. Yoo et al. (2017) studied the atomization and breakup characteristics of liquid jets at various spray conditions, using the large eddy simulation approach. A combined Eulerian-Lagrangian approach was employed to describe the spray field dynamics. The liquid column and the droplet breakup processes were simulated using a Kelvin-Helmboltz and Rayleigh-Taylor (KH-RT) hybrid wave breakup model. Reasonable agreement between model predictions and experimental data was demonstrated by the authors. However, TVD Range-Kutta method was used to solve the modeling equation without recourse to CFD codes. In a related work, Garai et al (2017) reported an experimental investigation of spray characteristics of kerosene and ethanol-blended kerosene using a gas turbine hybrid atomizer. The breakup length, cone angle and street width of the fuel stream were said to have been analyzed directly from backlit imaging for various fuel and air flow rates. It was concluded that breakup occurred earlier in the ethanolblended kerosene. A study on the spray and combustion characteristics of bio-ethanol-gasoline blended fuel based on fuel temperature was reported in Park et al (2016). The bioethanol test fuel was blended at volume ratios of $10 \%, 20 \%$ and $100 \%$ while fuel temperature were set at $-7.25^{\circ} \mathrm{C}$ and $35^{\circ} \mathrm{C}$ respectively. A visualization scheme that is similar to a high speed camera was used to capture spray images. The major conclusion from the study is that it is necessary to adjust the spray strategy and ignition timing to adopt bioethanol blended fuel as an alternative fuel. Ghahremani et al (2016) reported an experimental and theoretical study on spray behaviours of modified bio-ethanol fuel. They employed an unnamed atomization model to study spray atomization indicators such as Ohnesorg number, atomization index number and Sauter Mean Diameter and used a high speed visualization method for capturing spray images. The major conclusion is that increasing percentage of ethanol in the fuel blend results in increase in spray top penetration and decreases the projected spray area.

Feng (2016), investigated the effects of ethanol and gasoline addition on the spray and atomization characteristics of diesel spray, in a constant volume chamber and at various ambient and injection pressures. The spray tip penetration and cone angle were extracted from spray evolution process 
"Predictions of the Spray Characteristics of Model Gasoline, Ethanol and Ethanol-in Gasoline Fuel Blends"

that was recorded with high spatial and time resolution system. The results showed that the spray breakup and atomization process was promoted as gasoline blending ratio increased as gasoline blending ratio increased. However, they were silent about the optimum blending ratio and the corresponding spray characteristics.

2. Modeling of Breakup and Atomization

2.1: Blob Sheet Model
The blob sheet model is presented in fig 1 and the breakup rate is given as:

$$
\frac{d D_{p}}{d t}=k_{l} \frac{L_{A}}{\tau_{A}}
$$

The proportionality constant $k_{l}$ is subject to calibration, $L_{A}$ is the dominant length scale of atomization.

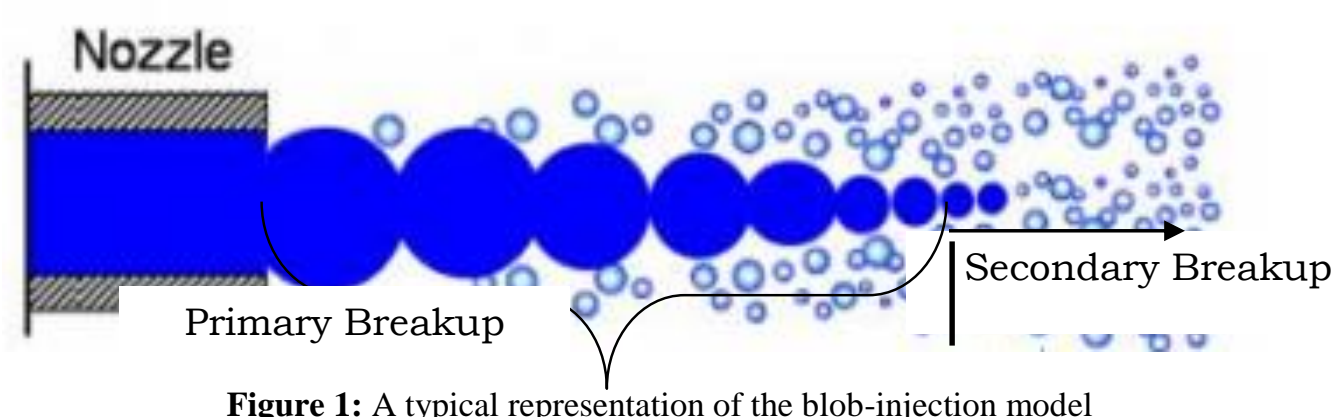

The model assumptions are:

- The length $\mathrm{L}_{\mathrm{A}}$ :

$$
L_{A}=C_{1} \times L_{t}=C_{2} \times L_{w}
$$

The atomization scale is the linear sum of the turbulence and wave growth time scales:

Turbulence quantity dissipation rate is given as:

$$
\begin{aligned}
& L_{t}^{0}=C_{\mu} \frac{k_{a v g}^{3 / 2}}{\varepsilon_{a v g}} \\
& \tau_{t}^{0}=C_{\mu} \frac{k_{a v g}}{\varepsilon_{a v g}}
\end{aligned}
$$

$\mathrm{C}_{\mu}=0.09$ and the average quantities are estimated

as:

$$
\begin{aligned}
& k_{\text {avg }}=\frac{u^{2}}{8(L / D)}\left[\frac{1}{c_{d}^{2}}-k_{c}-\left(1-s^{2}\right)\right] \\
& \varepsilon_{\text {avg }}=k_{\varepsilon} \frac{u^{2}}{2 L}\left[\frac{1}{c_{d}^{2}}-k_{c}-\left(1-s^{2}\right)\right]
\end{aligned}
$$

Turbulence length

$$
L_{t}(t)=L_{t}^{0}\left(1+\frac{0.0828 t}{\tau_{t}^{0}}\right)^{0.457}
$$

Time scale

$$
\tau_{t}(t)=\tau_{t}^{0}+0.0828 t
$$

Wave growth time scale $\tau_{w}=\frac{L_{w}}{U} \sqrt{\frac{\rho_{L}}{\rho_{g}}}$

\section{2: Wave Model}

The wave model (KH model) is where the stability analysis of round liquid jets is developed. The droplet breakup (Kelvin-Helmholtz instability) of liquid jet has initial radius $r$ and $\eta_{0}$ is an infinitesimal initial perturbation as shown in Fig 2.

Radius change of this droplet is calculated as:

$$
\frac{d r}{d t}=\frac{r-r_{n e w}}{\tau_{b u}}
$$

Where, $\tau_{b u}$ is the characteristic breakup time scale defined by:

$$
\tau_{b u}=3.788 B_{1} \frac{r}{\Lambda \Omega}
$$

And the new droplet radius given as;

$$
r_{\text {new }}=B_{0} \Lambda
$$

Where $B_{0}$ and $B_{1}$ are constants

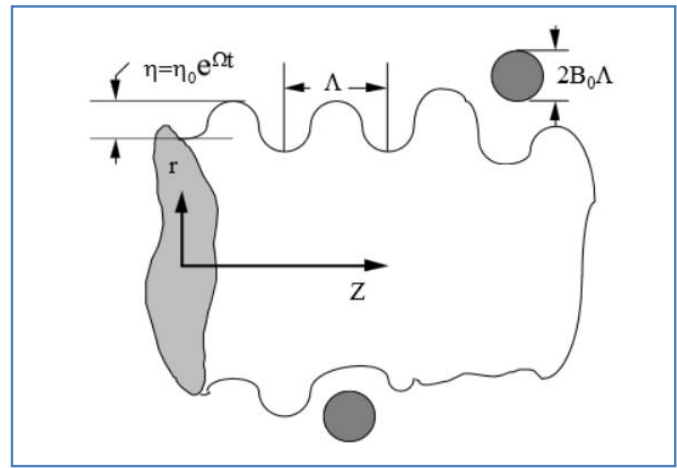

Figure 2: Kelvin-Helmholtz model 


$$
B_{0} \Lambda \leq r
$$

Maximum growth rate

$\Omega=\frac{0.34+0.38 W e_{g}{ }^{15}}{(1+z)\left(1+1.4 T^{0.6}\right)}\left[\frac{\sigma}{\rho_{l} r^{3}}\right]^{0.5}$

Wavelength

$\Lambda=9.02 r \frac{\left(1+0.45 Z^{0.5}\right)\left(1+0.4 T^{0.7}\right)}{\left(1+0.865 W e_{g}^{1.67}\right)^{0.6}}$

Where, $\quad Z=\frac{\sqrt{W e_{l}}}{\operatorname{Re}_{l}}=\frac{\mu_{l}}{\sqrt{\rho_{l} r \sigma}}$ Ohnesorge number,

$T=Z \sqrt{W e_{g}}$ Taylor number, and $W e_{g}=\frac{\rho_{g} r u_{r e l}^{2}}{\sigma}$ and

$W e_{l}=\frac{\rho_{l} r u_{r e l}^{2}}{\sigma}$ are gas and liquid Weber numbers,

respectively and $u_{\text {rel }}$ velocity of liquid droplet relation to stationary gas phase (Beale and Reitz, 1999).

\section{3: KH-RT Model}

This model consists of two modes of breakup: The KelvinHelmholtz (KH) breakup which accounts for instability in the waves growing and Rayleigh-Taylor (RT) breakup. KH instability model .Rayleigh-Taylor (RT) breakup is governed by the rapidly growing disturbances on the surface of the droplet. Wave, $\Omega_{R T}$ wavelength, $\Lambda_{R T}$ were given in equation (16) and (17), respectively:

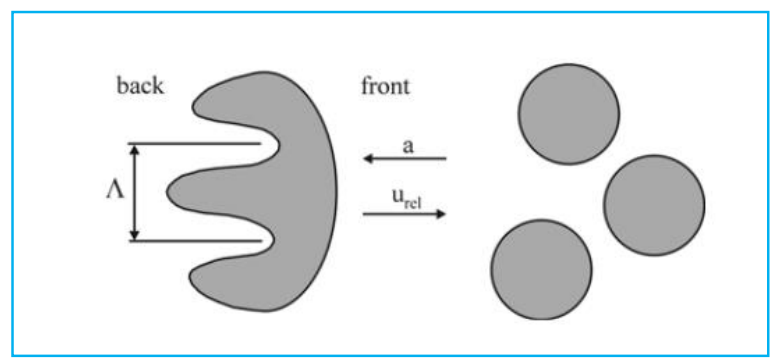

Figure 3: Rayleigh-Taylor (RT) instability.

$$
\begin{array}{r}
\Omega_{R T}=\sqrt{\frac{2\left[a_{d}\left(\rho_{l}-\rho_{g}\right)\right]^{1.5}}{3 \sqrt{3 \sigma}\left(\rho_{l}+\rho_{g}\right)}} \\
\Lambda_{R T}=2 \pi C_{R T} \sqrt{\frac{3 \sigma}{a_{d}\left(\rho_{l}-\rho_{g}\right)}} \\
a_{d}=\frac{3}{8} C_{d}\left(\frac{\rho_{g} u_{r e l}^{2}}{\rho_{l} r}\right)
\end{array}
$$

Where, $a_{d}$ is the droplet acceleration, $C_{d}$ is the injector nozzle's discharge coefficient and $C_{R T}$ is the modeling parameter.
The breakup time scale is expressed as:

$$
\tau_{R T}=\frac{C_{1}}{\Omega_{R T}}
$$

Where, $C_{1}$ is the modeling constant. When the growth time exceeds the characteristic Rayleigh-Taylor (RT) time, breakup occurs and the droplet is converted into parcels of smaller droplets. The new droplets formed are taken to be of uniform diameter.

\section{COMPUTATIONAL FRAMEWORK}

The spray injected into a constant volume cylinder is simulated using the Eulerian-Lagrangian approach. Small computational cells composing Meshes (8900) with fluid density, velocity, pressure and enthalpy were computed and stored on each computation cell. Gas (continuous) is simulated using the Eulerian formulation in ReynoldsAveraged Navier-Stokes (RANS) equation alongside Realizable k-e turbulence model which accounts for effect of turbulence fluctuations in the fluid phase. Similarly, the liquid (discrete or disperse) phase is treated using a Lagrangian formulation together with spray sub-models. The density, surface tension and viscosity of gasoline and ethanol fuels were computed internally and imported as input data. The inlet and exit temperatures and pressures were defined. A cylindrical system with consideration of all boundaries as walls and mesh coordinates were set to be symmetrical with an assumption of no heat loss. The mesh generation was taken to be one-quarter of a cylinder which was simulated by defining the process to be a transient compressible system where there were variations of pressure.

The reason for assuming symmetry in the cylinder is the use of cone injector model, hence it is considered a hollow injector atomizer so it can be symmetrical at $45^{\circ} \mathrm{C}$ per cross section. The inner nozzle diameter which was obtained from standard nozzle design is taken to be $100 \mu \mathrm{m}$. The study of spray characteristics of gasoline fuel ((G100) $\mathrm{C}_{7} \mathrm{H}_{16}$ ) was done by simulation using OpenFOAM source code which runs on Linux platform. This analysis was effected using SimFlow to generate meshes for the simulation and run. The mesh and results files were saved to the OpenFOAM file format and visualized in ParaView software. Further analysis was done with MatLab by saving in the MatLab directory. In the simulation, only a quarter of cylinder was used in the simulation. Two of the boundaries were set to symmetry and the remaining boundary set to wall. The spray foam solver is the solver type that was used to simulate a transient, compressible, reacting and noncombustible fuel injection process. High pressured fuel at $5 \mathrm{MPa}$ at $300^{\circ} \mathrm{K}$ was injected into high temperature $\left(800^{\circ} \mathrm{K}\right)$ stagnant air at a velocity of $100 \mathrm{~m} / \mathrm{s}$. The Turbulence Model of RANS - Realizable k-e model, with heat transfer model of Ranz-Marshall as well as phase change model which is 
"Predictions of the Spray Characteristics of Model Gasoline, Ethanol and Ethanol-in Gasoline Fuel Blends"

liquid evaporation-boil model was adopted in boundary interaction (rebound) in secondary atomization.

\section{RESULTS AND DISCUSSION}

4.1 Spray Evolution of the Gasoline (G100) Fuel

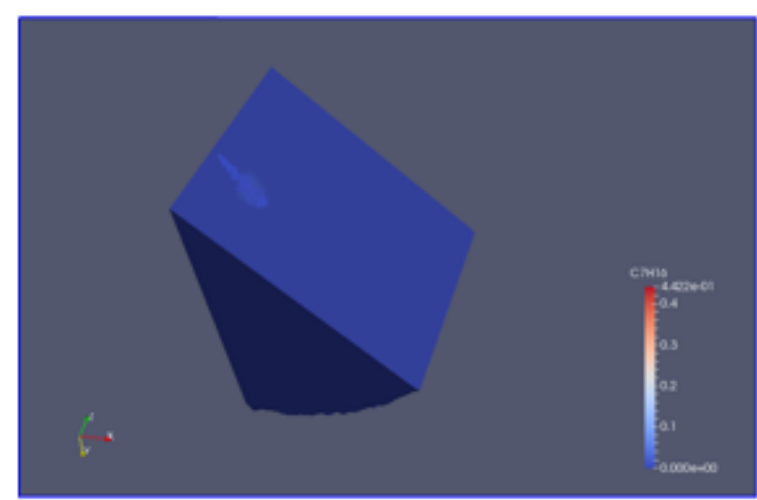

Figure 4.a: Energizing time $(0.00015 \mu \mathrm{s})$

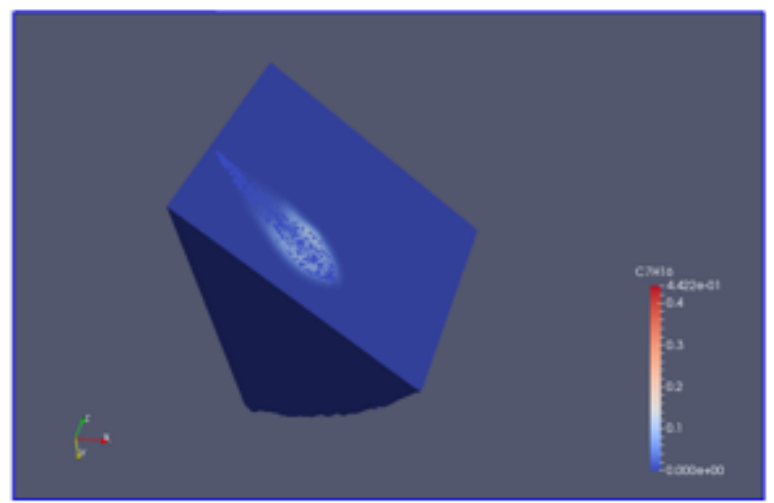

Figure 4.c: Energizing time (0.000445 $\mu \mathrm{s})$
The result files generated in SimFlow/OpenFOAM were post processed in ParaView. The Figures 4.a - d, show the images of the spray development for model Gasoline (G100) fuel.

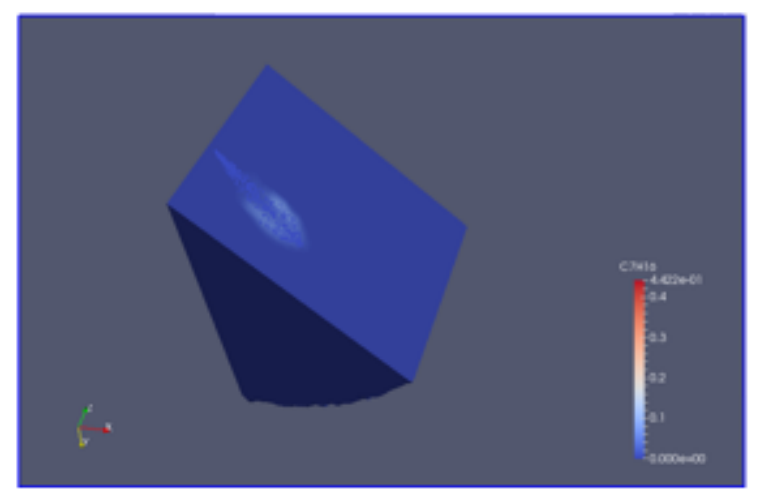

Figure 4.b Energizing time $(0.00032 \mu \mathrm{s})$

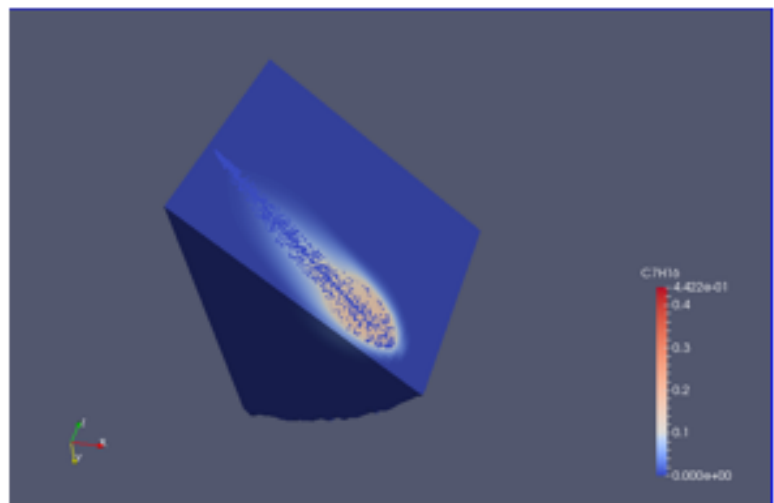

Figure 4.d Energizing time $(0.0008 \mu \mathrm{s})$

4.2. Spray Evolution at four Cone Injection Angles at time steps of $0.0001 \mu$ s, $0.0002 \mu \mathrm{s}, 0.0003 \mu$ s and $0.00075 \mu$ s respectively: Figure 5a to $5 \mathrm{~d}$ show the spray evolution at four cone injection angles $\left(20^{\circ}, 30^{\circ}, 40^{\circ}\right.$ and $\left.50^{\circ}\right)$ at time steps of $0.0001 \mu \mathrm{s}, 0.0002 \mu \mathrm{s}$, $0.0003 \mu \mathrm{s}$ and $0.00075 \mu \mathrm{s}$. This injection process represents time frame of injection with respect to injection angular variations. It could be deduced from the figures that with longer injection time frame and wider injection angle, the penetration width was wider and the penetration length deeper (longer) resulting in better atomization.

Cone Angle $=20$ degrees

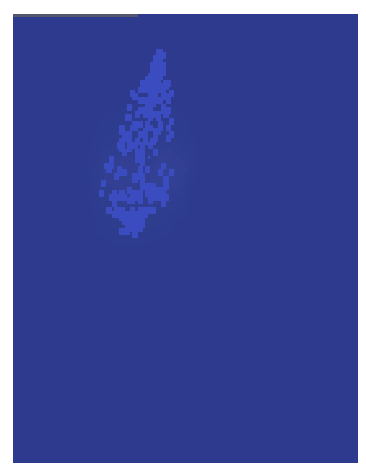

Cone Angle $=30$ degrees

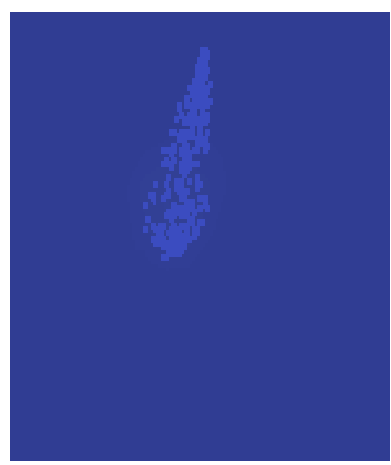

Cone Angle $=40$ degrees

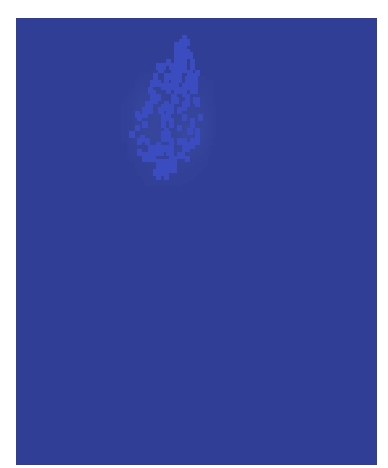

Cone Angle $=\mathbf{5 0}$ degrees

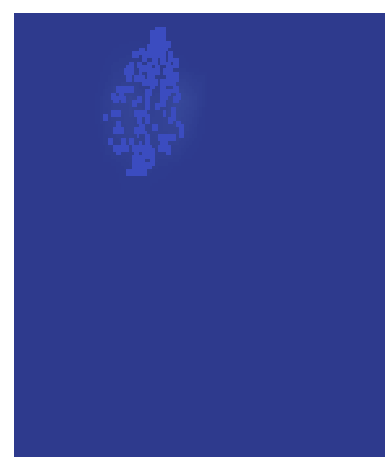

Fig 5a. $0.0001 \mu$ s after injection 

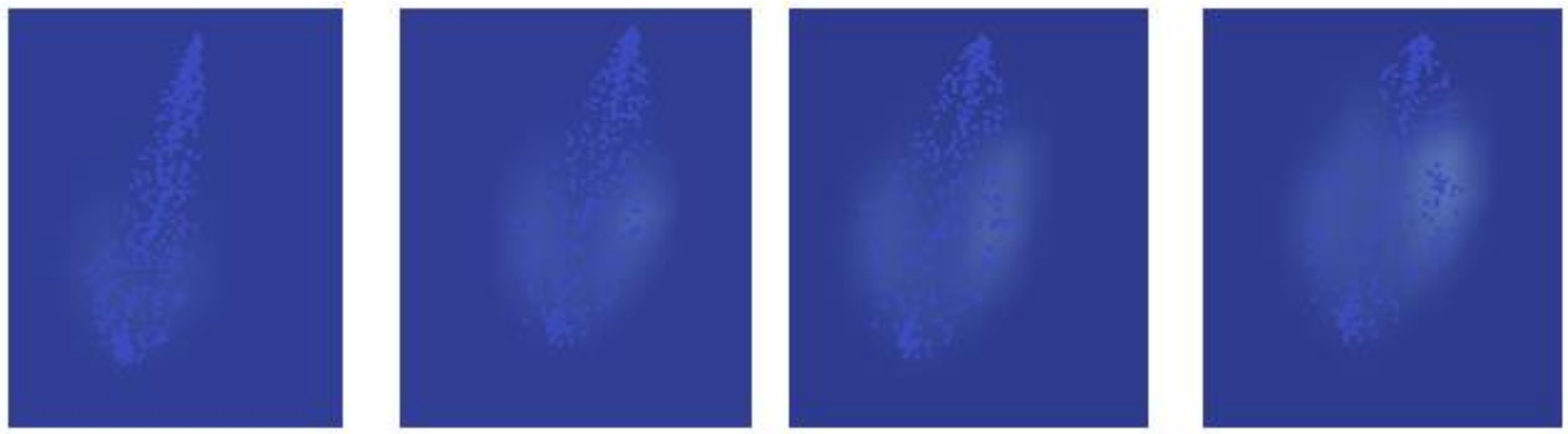

Fig 5 b. $0.0002 \mu$ s After Injection
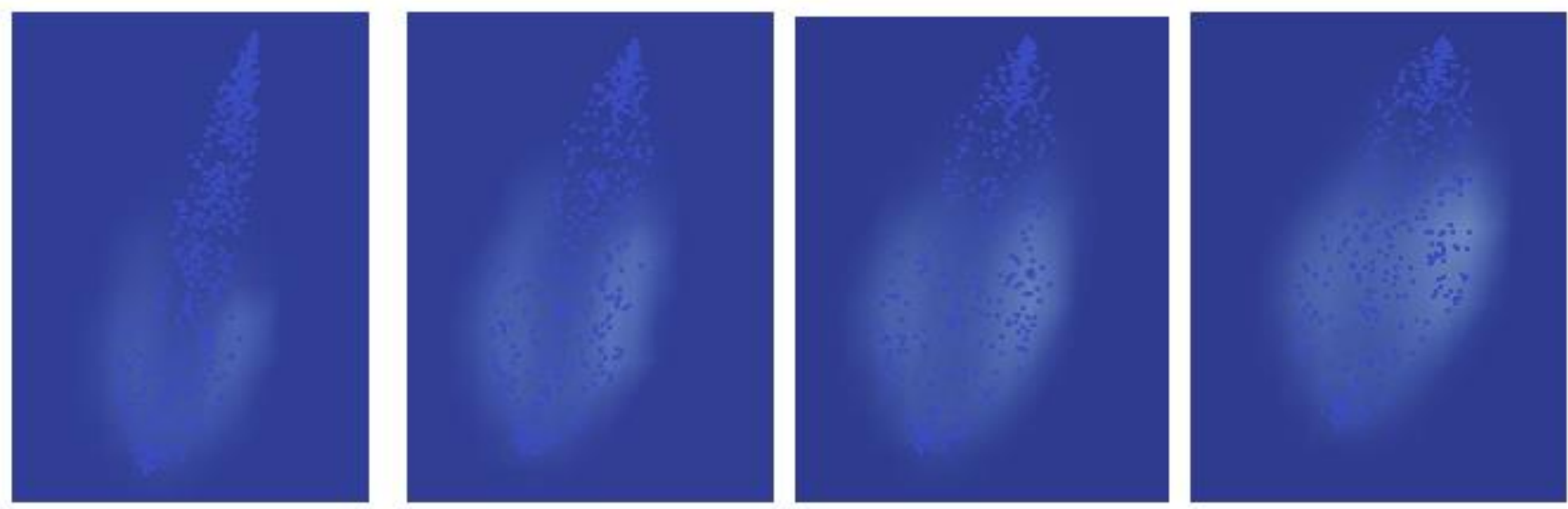

Fig 5c. $0.0003 \mu$ s After Injection
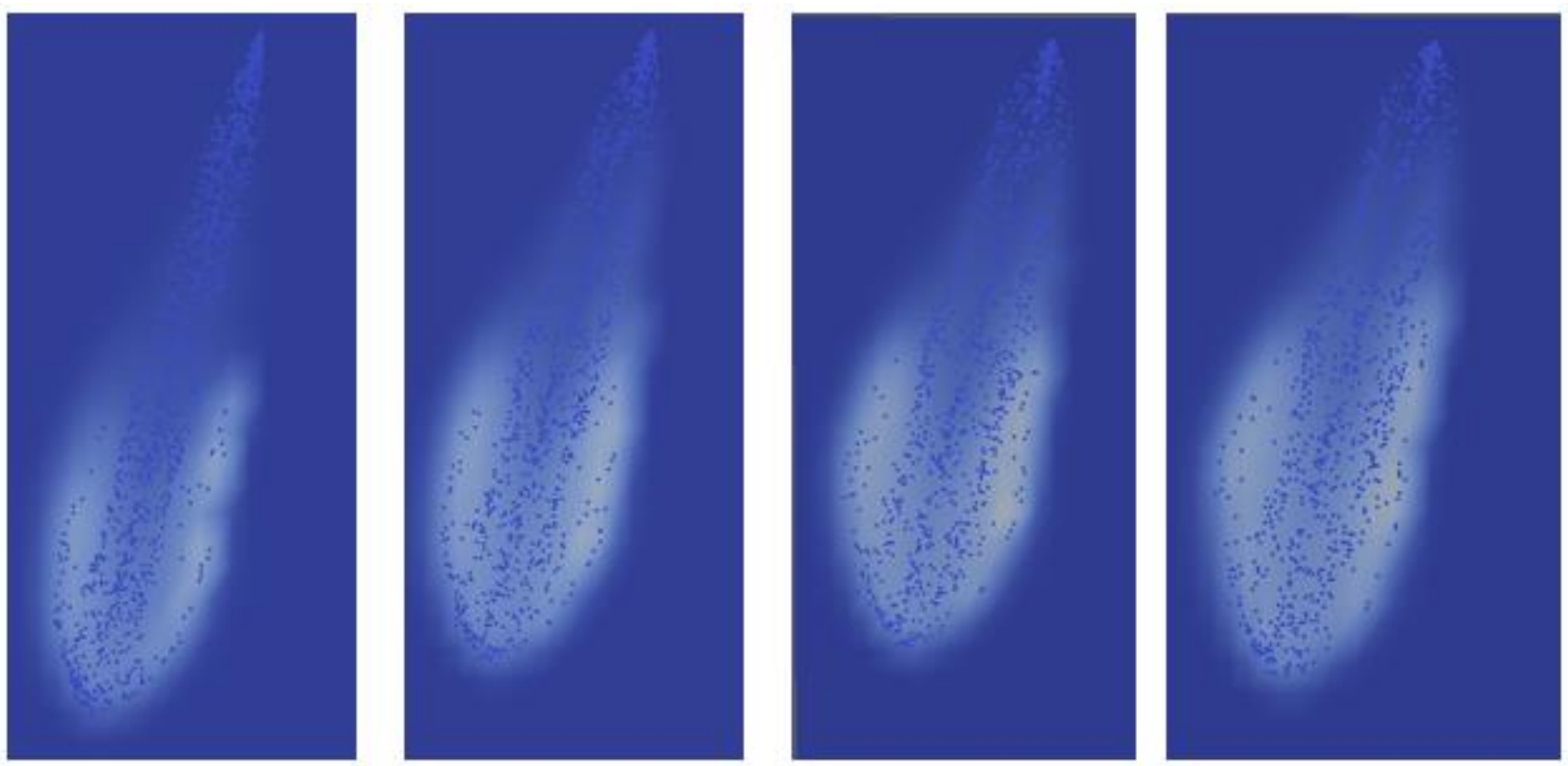

Fig 5d. $0.00075 \mu$ After Injection

\section{3: Other Spray characteristics}

Figure 6 shows the droplet diameter against number of particles. It indicates that as the droplet diameter increases the particles density decreases. This suggests that where the particle size is small the electrostatic force of attraction between them increases because the ionic radii becomes small. The droplet diameter increases up to $1.75 \times 10^{-5} \mathrm{~m}$ after which it drops because the particle density even in this 1163 range decreases t. Most of the particle pumped will go out with the exhaust as without combustion taking place beyond this point which indicates that it will be waste of fuel hereafter. Again, according to figure 6, when the particle diameter is small the viodage between particles are small, hence particles tend to cluster in a particular zone. As the diameter increases, the density of the clusters become smaller. The number of particles increases while the particle 
density decreases as a result of atomization. It peaks at diameter between 1.5 and $2.0 \mu \mathrm{m}$ at particle range of 45 . Beyond this point the particle density begins to build again due to coaliscence. Hence the curve is a normal distribution curve which is skewed a little. The apex of this plot shows some noise before the plot descends downwards. The Rosin Rammler distribution model was used to generate the number of spray particles injected into the cylinder as shown in figure 7. Rosin Rammler distribution is adopted because its well suited for spray atomization distributions. The Rosin Rammler cummulative particle size distribution plot for spray droplets shows that with an exponential rise in the particle diameter, the cumulative effect increases which shows that there will be better combustion up to the pick $2 \mathrm{x}$ $10^{-5} \mathrm{~m}$ of droplet diameter. This figure 7 is derived from figure 6 and it is the summation of particle diameter over the range of number of particles. The curve is exponentially distributed. Figure 8 is the injected droplets profile with time at pressure of 5MPa. This plot shows the engine performance in terms of atomization. From the zero axis between 0.00 to $0.5 \mu \mathrm{s}$, the number of injected droplet, up to 6000 increased linearly. This means that in this region injected parcels were proportional to time of energizing $(\mu \mathrm{s})$. Inference here is that the more the number of droplets injected the more atomization took place. Beyond this point the curve became somewhat wavy in a plateau form. This graph shows the effectiveness of atomization within a short period of time of $0.5-1 \mu$ s when atomization takes place close to 7000 injected droplet particles. The most essential range to assess the extent of atomization of fuel is therefore 7000 droplet particles released into the combustion chamber. Beyond this time there is only a marginal increase in the number of particle. Figure 9 shows the Sauter mean diameter (SMD) at injection pressure of 5MPa and injection cone angle of $20^{\circ}$. Sauter mean diameter (SMD) decays exponentially from 100 to $50 \mu \mathrm{m}$ shows SMD drops and experiences decay exponentially in time interval between 0 and $1000 \mu$ s., From $50 \mu \mathrm{m}$ down to $40 \mu \mathrm{m}$, the SMD drops sharply- linearly and then from $40 \mu \mathrm{m}$ to $20 \mu \mathrm{m}$ displays negative exponential curve and does not experience any further change beyond $2000 \mu \mathrm{s}$. The observed trend alludes to the fact that SMD is insensitive to change with time in the value ranges of $2000 \mu \mathrm{s}$ to $5000 \mu \mathrm{s}$. Despite the cone injection angle variation of $20^{\circ}, 30^{\circ}, 40^{\circ}$ and $50^{\circ}$, the SMD profile behaves similarly with varying energizing times at $5 \mathrm{mPa}$ injection pressure as in figure 9 . Figure 10 just like fig 9 shows four distinct atomization regimes. Reading the plot in fig 9 from the y axis show that injection angle of $30^{\circ}, 40^{\circ}$, $50^{\circ}$ and $20^{\circ}$ present better atomization in that order in relation to $250 \mu$ s time after injection. Between $250 \mu$ s and $1000 \mu \mathrm{s}$ time after injection atomization rate shows differently by presenting $30^{\circ}, 20^{\circ}, 40^{\circ}$ and $50^{\circ}$ in that order, but from $1000 \mu$ s to $1700 \mu$ s injection angles depict that $20^{\circ}$ atomizes most, followed sequentially by $30^{\circ}, 40^{\circ}$ and $50^{\circ}$. The fourth and final distinct regime show that from injection time of $1750 \mu$ s through $5000 \mu$ s atomization is dominated by angular injection in the following pattern $50^{\circ}, 40^{\circ}, 30^{\circ}$ and $20^{\circ}$.

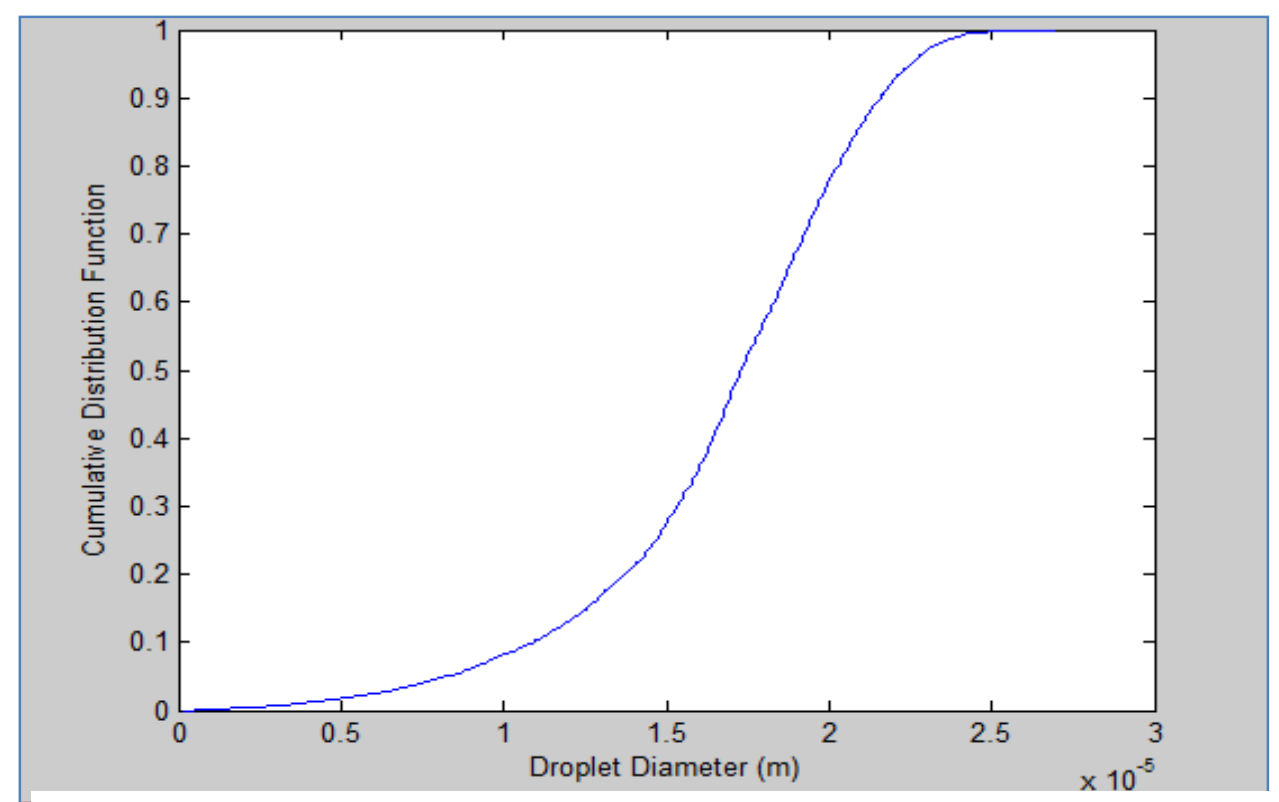

Figure 6. G100 Droplet size distribution at 5.0e-3(ms) after energizing 
"Predictions of the Spray Characteristics of Model Gasoline, Ethanol and Ethanol-in Gasoline Fuel Blends"

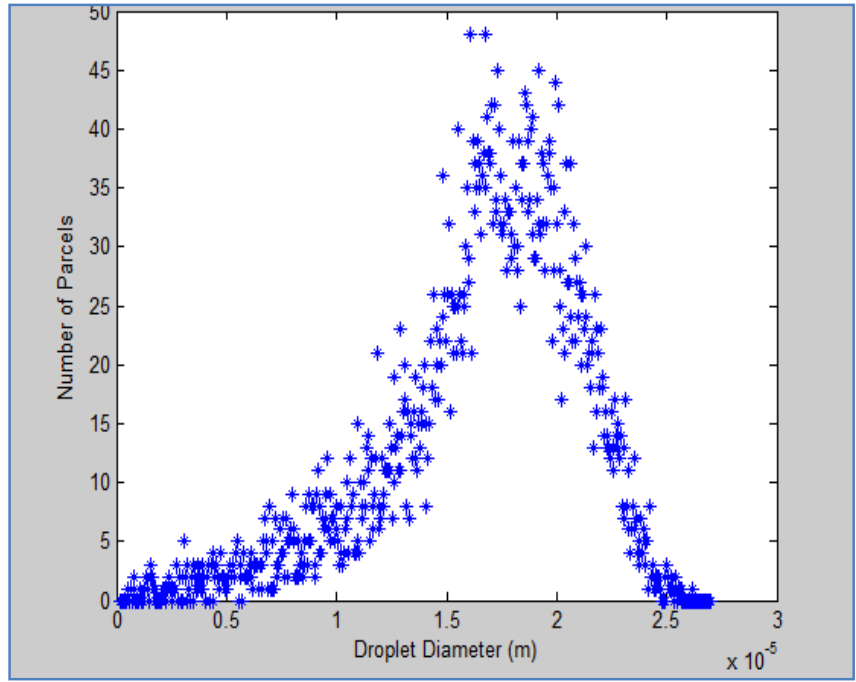

Figure 7: Rosin Rammler Distribution for the Spray droplets at $5 \mu$ s after energizing.

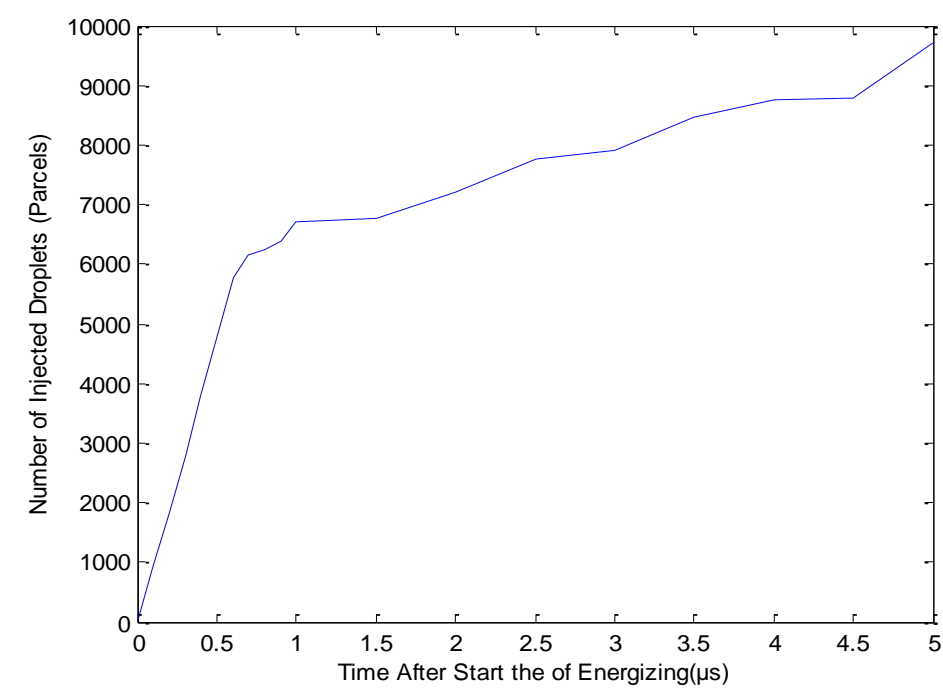

Figure 8: Injected droplets profile with time at pressure of 5MPa

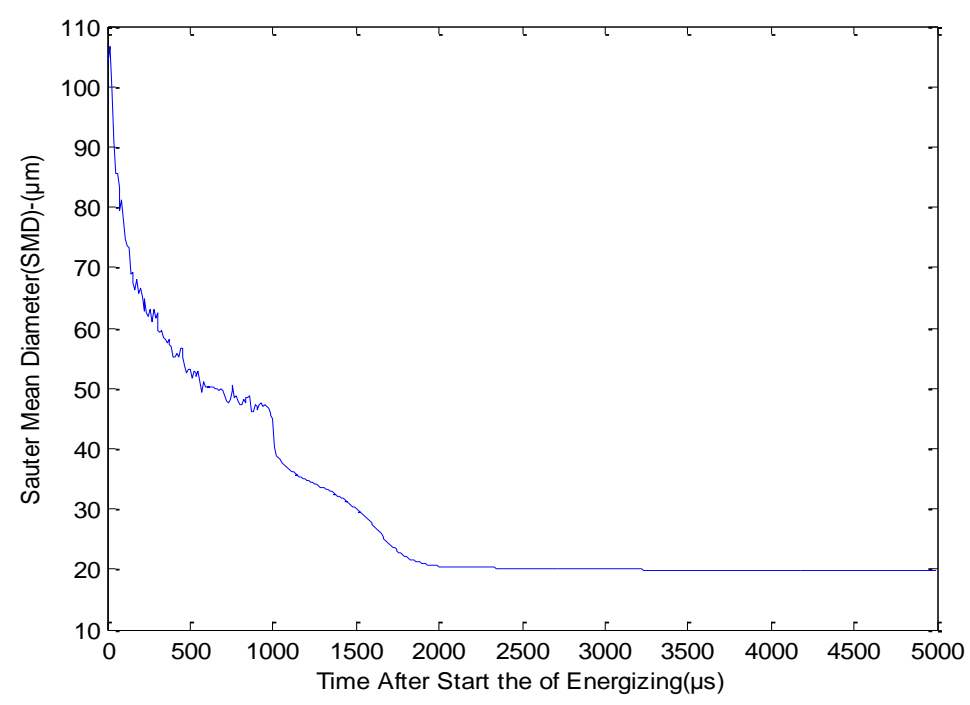

Figure 9: Sauter Mean Diameter (SMD) at injection pressure of 5MPa and injection cone angle of $20^{\circ}$ 


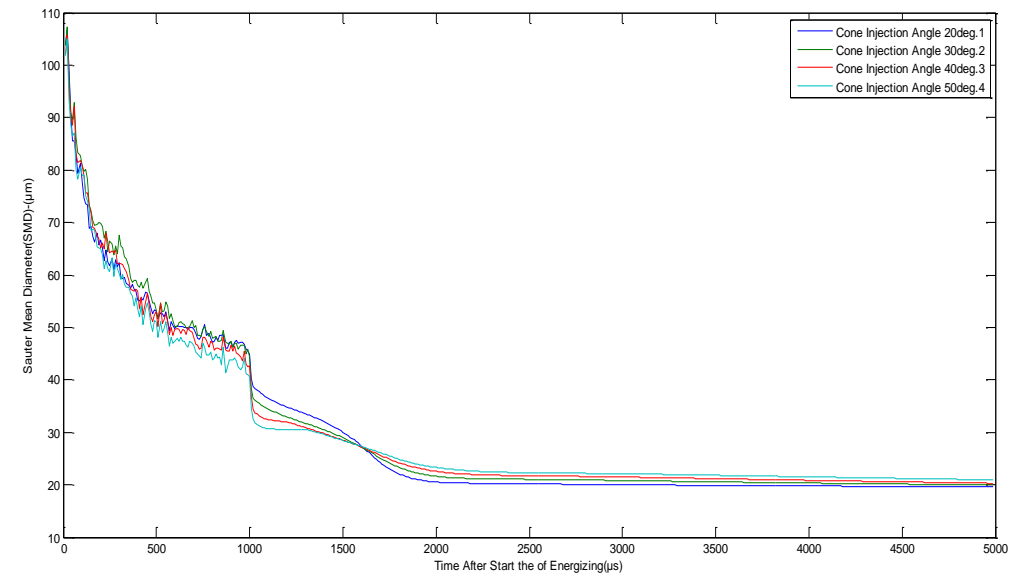

Figure 10: Sauter Mean Diameter (SMD) at injection pressure of 5MPa for four cone injection angles for gasoline

\section{CONCLUSION}

Predictions on the spray characteristics of model gasoline fuels and its hybrids have been presented in this paper. The observed trends revealed some valuable insights in the understanding of atomization as a precursor to combustion. It is hoped that the opinions expressed in this paper would serve as corner stones for further computation fluid dynamics (CFD) investigations around the domain of model fuels as against financially burdensome experimental investigations that demand high precision equipment. .

\section{6: NOTATION}

CFD

DDM

DNS

E100

E15

E50

E85

ELSA

$F$

G100

GASHOL

$\mathrm{k}$

$\mathrm{k}_{\mathrm{c}}$

k-H

$\mathrm{L}, \mathrm{D}$

LES

LISA

LPT

RANS

RT

$\mathrm{S}$

SMD

SME

TAB

TAB

$3 \mathrm{D}$
Computation fluid dynamics

Discrete Droplet Method

Direct Numerical Simulation

Ethanol fuel

15-85\% Ethanol-Gasoline blended fuel

50-50\% Ethanol-Gasoline blended fuel

85-15\% Ethanol-Gasoline blended fuel

Eulerian-Lagrangian Spray Atomization

The external forces

Gasoline fuel

Gasoline-ethanol fuels

Kinetic energy

Constant taking into account losses in

contraction corner

Kelvin-Helmholtz

Nozzle length and diameter, ,

Large Eddy Simulation

Linearized Instability Sheet Atomization

Lagrangian Particle Tracking

Reynolds Averaged Navier-Stokes

Rayleigh-Taylor

Area ratio at the nozzle contraction

Sauter Mean Diameter

Soybean oil methyl ester

Taylor Analogy Breakup

Taylor Analogy Breakup

Three dimensional $c$

$d$

$f(d)$

$k$

$m(t)$

$r$

$t$

$x$

$a_{d}$

$B_{0}, B_{1}$

$\mathrm{C}_{\mathrm{d}}$

$C_{D}$

$C_{d}$

$C_{R T}$

$C_{b}, C_{d}, C_{f}, C_{k}$

$d_{\max }, d_{\min }$

diameters

$d_{i n j} \quad$ Injector nozzle diameter

$F_{D} \quad$ Drag force,

$k_{s} \quad$ Spring's constant

$k_{\max } \quad$ Wave number corresponding to the maximum growth rate

$k_{\varepsilon} \quad$ Constant for average turbulent energy dissipation, set to 0.27 ,

$K_{b r} \quad$ Constant - breakup regime

$P_{a} \quad$ Ambient gas pressure,

$P_{i n j}$

$S_{1}, S_{2} \quad$ Spray tip penetration lengths before and after breakup. 


$\begin{array}{ll}t_{b} & \text { Breakup time, } \\ \mu_{t} & \text { Turbulent viscosity } \\ \varepsilon & \text { Turbulence dissipation } \\ \overline{\Omega_{i j}} & \text { Mean rate-of-rotation tensor } \\ \omega_{k} & \text { Angular velocity } \\ \rho_{L} & \text { Fuel density } \\ \rho_{a} & \text { Ambient gas density, } \\ \theta & \text { Spray cone angle, and } \\ \rho_{g}, \rho_{l}, \sigma & \text { Gas and liquid densities and surface } \\ \text { tension } & \\ \omega_{\max }, h_{b} & \text { Sheet thickness at the breakup location } \\ \omega_{\max } & \text { Maximum growth rate } \\ \rho_{r} & \text { Air-fuel density ratio } \\ \mu & \text { Velocity }\end{array}$

\section{REFERENCES}

1. C.E. Ejim, B.A. Fleck and A. Amirfazli,"Analytical study for atomization of biodiesels and their blends in LI typical injector: Surface tension and viscosity effects". Fuels, 86, 1 534-1 544, 2007.

2. R. Lebas, T. Menard; P.A. Beau; A. Berlement; E.X. Demoulin,"Numerical Simulation of primary breakup and atomization: DNS and modeling study". International Journal of Multiphase Flow, 35, 247-260, 2009.

3. J.Goa, D.Jiang and Z.Huang, "Spray properties of alternative fuels, a comparative analysis of ethanol-gasoline blends and gasoline, Fuel 86, pp. 1645-1650, 2007.

4. P. G.Aleiferis, J. S.Malcolm, A. R.Todd, A.Cairns and H.Hoffmann,"An optical study of spray development and combustion of ethanol, iso-octane and gasoline in a DISI engine", SAE Paper, 010073, 2008.

5. R. D.Reitz, "Modeling Atomization Processes in High-Pressure Vaporizing Sprays"Atomization and Spray Technology Journal, Vol. 3, pp. 309-337, 1987.

6. S.Hossainpour and A.R. Binesh, "Investigation of fuel spray atomization in a DI heavy-duty diesel engine 'and comparison of various spray breakup models". Fuel, 88, 795-805, 2009.

7. X.Jiang, G. A.Siamas, K.Jagus and T. G.Karayiannis, "Physical modelling and advanced simulations of gas-liquid two-phase jet flows in atomization and sprays",Progress in Energy and Combustion Science, Vol. 36 pp. 131-167, 2010.
8. O. Lijuan, J. Lin and H. Xiong, "Simulation of droplet-gas flow, in theeffervescentatomizationspraywithan impinging plate". Fluid flow and transport phenomena, 17(1), 8-19, 2009.

9. S.H.Park, J. K. Hyung; K. S. Hyun; S.L. Chang "A study on the fuel injection and atomization characteristics of Soybean Oil Methyl Ester (SME)"International journal of heat and fluid flow, 30, 108-116, 2009.

10. S.H. Park, J. K. Hyung, K. S. Hyun; S. L. Chang."Experimental and numerical of sprayatomization characteristics of biodiesel fuel in various fuel and ambient temperature conditions.International".Journal of Heat and Fluid Flow, 30, 960-970, 2009b.

11. S. Kim, J. W.Hwang and C.S. Lee,"Experiments and modeling on droplet motion and atomization of diesel and bio-diesel fuels in a cross-flowed air stream". International Journal of Heat and Fluid Flow, 31,667-679, 2010.

12. Hyung Jun Kim, Su Han Park, Chang Sik Lee, "A study on the macroscopic spray behaviour and atomization characteristics of biodiesel and dimethyl ether sprays under increased ambient pressure". Fuel Processing Technology, 91, 354363, 2010.

13. J.Shinjo, and A. Umemura, "Surface instability and primary atomization characteristics of straight liquid jet sprays"International Journal of Multiphase Flow, 37, 1294-1304, 2011.

14. L. Zhouhang, W. Yuxin, C. Chungrong, Z. Hai, G.Yingli and KeijiT."Mixing and atomizationcharacteristics in an internal mixing twin-fluid atomizer".Fuel, 97, 306-314, 2012.

15. S. Lee and S. Park. "Experimental study on spray break-up and atomization processes from GDI injector using high injection pressure up to $30 \mathrm{MPa}$ ". International Journal of float and Fluid Flow 45, 14-72, 2014.

16. D. Cipolat, and D.Valentim, "Comparison of theoretical and experimental diesel and DMe injection spray characteristics", 107, 36-43, 2013.

17. Z.Hui, L.Hai-Feng, X. Jian-Liang, L. Wei-Feng and $\mathrm{C}$. Wei, Breakup and atomization of a round coal water slurry jet by an annular air jet. Chemical Engineering Science, 78, 63-74, 2012.

18. Z.H.Li, B.Q. He and H. Zhao,"Application of a hybrid breakup model for the spray simulation of a multi-hole injector used for a DISI gasoline engine". Applied Thermal Engineering 65, 282292, 2014.

19. De-Jun Jiang, Hai-Feng Liu, Wei-Feng Li, JianLiang $\mathrm{Xu}$, Fu-Chen Wang, XinGong,"Modeling atomization of a round water jet by a high-speed 
annular air jet based on the self-similarity of droplet breakup. Chemical Engineering Research and Design", 90, 1 85-192, 2012.

20. A.D.Vita and L.Allocca,"Experimental analysis and CFD simulation of GDI sprays," SAE Technical Paper 2003-01-0004, 2003.

21. N.Kawahara, E.Tomita, D. Kasahara, T. Nakayama and M. Sumida,"Fuel breakup near nozzle exit of high-pressure swirl injector for gasoline direct injection engine", SAE Technical Paper 2004-010542, 2004.

22. H.P.Su, J.K.Hyung, K. S.Yyun and S.L.Chang,"Atomization and spray characteristics of bioethanol and bioethanol blended gasoline fuelinjected through a direct injection gasoline injector",International Journal of Heat and Fluid Flow, Vol.30, pp. 1183-1192, 2009a.

23. H.P.Su, J.K.Hyung, K.S.Yyun and S.L.Chang,"Experimental and numerical analysis of spray-atomization characteristics of biodiesel fuel in various fuel and ambient temperatures conditions", International Journal of Heat and Fluid Flow, Vol.30, pp. 960-970, (2009b).

24. P. G.Aleiferis, J.Serras-Pereira, Z.vanRomunde, J.Caine and M.Wirth,"Mechanisms of spray formation and combustion from a multi-hole injector with E85 and gasoline, Combustion and Flame" Vol.157, pp. 735- 756, 2010.

25. C. A.Chryssakis, D.N.Assanis, and F. X.Tanner,"Atomization Models", Handbook of Atomization and Sprays, pp. 215-231 [Chapter 9], 2011.

26. R. D. Reitz and F. V.Bracco,"Mechanisms of breakup of round liquid jets,"The Encyclopedia of Fluid Mechanics, N. Cheremisnoff, Ed., Gulf Publishing, Houston, Texas, Vol. 3, pp. 233-249, [Chapter 10]. 1986

27. F. Leonardo, T.Alfredo and A.M. Alvarez, "Sauter Mean Diameter Determination for the Fine Fraction Suspended Sediments using a LISSt-25X Diffractometer, Elsevier, pp 364-368, 2012.

28. D. Jing, Experimental and Numerical Studies of Fuel Spray, $\mathrm{PhD}$ thesis, school of mechanical engineering, university of Birmingham (2015).

29. A.Ghasemi, R. M.Barron and R.Balachandar; Spray induced air motion in single and twin ultrahigh injection diesel sprays, Fuel 121, pp 284-297 (2014). 